\title{
All Too Human: Recontextualizing Deleuze and Levinas on Art
}

\author{
Professor Tina Chanter
}

Kingston University

\begin{abstract}
Although they elaborate it differently, both Levinas and Deleuze appeal to the notion of rhythm as decisive for understanding art. Drawing on their analyses I discuss the work of several artists featured in a current exhibit showing at the Tate Britain, All Too Human: Bacon, Freud and a Century of Painting Life. In addition to Francis Bacon and Lucian Freud, I discuss the work of Paula Rego and Lynette Lydiam-Boakye. Vlad lonescu suggests that a productive approach to writing about art after Deleuze and Guattari would be to inquire into 'how constellations of sensation modify our perceptions of the world' (2017, p. 22). I take up lonescu's suggestion, but also recontexutalize it in order to offer a politicized account of how the exhibit is framed. At the same time I draw on feminist and race theory to discuss the work of Rego and Lydiam-Boakye, thus also recontextualizing Levinas's and Deleuze's analyses of art. The questions this paper addresses include: What makes these paintings work, and how do they function? How do their aspects and rubrics operate? What creates their rhythms? How do they operate as an assemblage?
\end{abstract}

Keywords: Art, Philosophy, Rhythm, Francis Bacon, Lucian Freud, Paula Rego, Lynette Lydiam-Boakye, Levinas, Deleuze, feminist \& race theory

\section{Introduction}

Clearly there are major philosophical differences between Levinas and Deleuze, perhaps most obviously, the fact that while Deleuze embraces a philosophy of immanence, Levinas casts suspicion on immanence as the sphere of the same, the totalizing world of the said, as opposed to the saying, and the ethical call of face that breaks through immanence, transcending totality. So too, while art plays the role of prologemena to the infinite ethical demand placed on the I by the other, such that its anarchic force is ultimately found to be in need of tempering by a philosophy that answers to the ethical relation, there is no such subordination of art to philosophy in Deleuze, who prefers to envisage the relationship of one art and philosophy as one of transversal. In this paper, I want to put aside this undoubtedly fundamental philosophical divergence in order to focus on a striking similarity in how rhythm plays a key role for both Levinas and Deleuze in their conception of art.

In order to provide an initial sketch of the role accorded to rhythm by Levinas and Deleuze, I will focus on the texts in which I think the continuity of their accounts in this regard is most evident, namely Levinas's discussion of Maurice Blanchot in 'The Servant and Her Master' (1989) and Deleuze's discussion of painting in Francis Bacon: The Logic of Sensation (2017).

The rhythm of poetry Levinas finds in Blanchot is not unlike that which Deleuze finds in Bacon's art, whose images are not for the sake of representation. It is a saying that unsays itself, a language that does not totalize. Levinas identifies in Blanchot's Waiting Forgetting a 'tautological rhythm which punctuates dialogue itself, because of the monotonous droning which immediately closes off the avenues of communication (1989, p.152). For Deleuze, it is in the differentiations of colour between Bacon's triptychs that he 'discovers rhythm as the essence of painting' (2017, p.xiv). According to Levinas the "language of poetry becomes for Blanchot a language which contradicts itself. . . Affirmation is followed, often in the same proposition, by its negation. Saying lets go of what it grasps' (1989, p.156). Describing the functioning of Blanchot's language, Levinas says, 'The silence which occurs does not put a stop to the rustling' (p.154). Blanchot's 'discontinuous and contradictory language' ( $p .156)$ conveys the sense in which language undoes itself: 'in place of the beginning, [there is] a sort of initial void, an energetic refusal to let the story begin' ([p. 22] p.153). For Levinas, 'Blanchot calls into question the seemingly incontestable claim of a certain sort of language to be the privileged bearer of what is meaningful ... Does the meaningful depend on a certain order of propositions, constructed according to a certain grammar so as to constitute 
a logical argument? or does meaning cause language to explode and then signify amidst these fragments?'... Waiting Forgetting refuses to grant the philosophical language of interpretation . . . the dignity of the ultimate language.' (p.153). Levinas sees in 'art and poetry that exceptional event - that sovereign forgetfulnesss - which frees language from its servitude towards the structures in which the said prevails (p.153). For him, 'Poetic language gives sign without the sign being a bearer of signification through relinquishing signification' (p.156). Quoting Blanchot, Levinas says, 'No-one here wishes to be bound by a story' ([p. 22] p.157).

If the rhythm of Blanchot's language consists for Levinas in affirming and then negating, in saying then letting go, for Deleuze, the shifting tensions between each painting in Bacon's triptychs according to which structure, figure and contour relate to one another perform a similar function. It is the 'coexistence' of the 'movements' between these 'three basic elements' (2017, p.24) of Bacon's painting, structure, figure and contour that constitutes 'rhythm' (p. 25). Indeed, it is 'rhythms alone that become characters' ( $p$. xiv). In a first movement, which goes 'from the structure to the Figure' the contour first isolates the figure 'in a completely closed word' (p. 24). Here the contour appears as 'a round area, an oval, a bar, or a system of bars' ( $p$. 24). Then in a second movement, from the figure to the material structure, the contour changes ... acting as a deformer' (p.24). It 'turns into the half sphere of the washbasin or umbrella, the thickness of the mirror ... The Figure is contracted or dilated in order to pass through a hole or into the mirror' (p. 24). Then the figure 'tends to return to the field of color, to dissipate into the structure ... through the intermediary of the contour, which no longer acts as a deformer ... thus this most closed of worlds was also the most unlimited (p.24). Just as Levinas follows the back and forth, contradictory movement of Blanchot's language, which affirms then negates, so in this series of variations or transformations effected between the structure, figure and contour, so Deleuze finds in Bacon a completely closed world and the most unlimited of worlds, he sees the contour as acting to deform the figure, yet no longer acting as deformer.

It is the 'confrontation' (p.xiii) between the figure and 'large fields of color' which 'are themselves divided into sections or crossed by tubes or very thin rails, or sliced by a band or largish stripe' and which as such form 'armature, a bone structure' (xi), it is 'their solitary wrestling in a shallow depth, that rips the painting away from all narrative but also from all symbolization' (p.xiii). Beyond 'narration' (p. 50) and 'figuration' (p.96), for Deleuze, Bacon's paintings do not represent or signify, but express the 'violence of sensation' ( $p$.xiii). For Levinas, Blanchot's 'literary writing proper provides above all a new sensation' (1989, p.153) and in doing so it explodes the instant, letting the instant die so that time has to begin again, rather than engaging in the coherent language of philosophy, which joins up the past, present, and future, in a language of retention and protention, the language of consciousness, that of the transcendental ego, the language of the same (see Peters, 1997). Blanchot's language interrupts the continuity and coherence of philosophy. 'Poetry', says Levinas, 'can be said to transform words, the tokens of a whole, the moments of a totality, into unfettered signs, breaching the walls of immanence, disrupting order' (1989, p.156). It undoes 'the structures of language' (p.156). Bacon's painting 'breaks with figuration', and, with the possible exception of Michelangelo, Deleuze thinks that never has anyone done so by 'elevating the Figure to such prominence' (2017, p.xiii).

Deleuze's emphasis is on invisible forces, sensation and the differential rhythms that are themselves the only characters in painting rather than representation and meaning, and Levinas's emphasis is on the alterity and exoticism of art as interrupting and breaking through the totality of coherent meaning, where the rhythm of art imposes itself as captivating, has a hold over us, so that 'there is no longer a oneself, but rather a sort of passage from oneself to anonymity.' (1987, $p$. 4) On the surface, the potential for a politically inflected Deleuzian or Levinasian infused account of art might seem unpromising. Yet I want to ask: what if it were not representation or coherence as such that was at issue, but rather the circulation of variants of one dominant narrative, which becomes so dominant that other stories cannot be seen as legitimate-cannot be seen in any meaningful sense? What if the sensation that both Levinas and Deleuze take art to uncover can bring into view new concepts of what it is that can be represented, narrated or rendered philosophically intelligible?

As indicated above, Levinas subordinates art to the authority of philosophy ultimately, and as such does not attempt to introduce a new approach to art although this does not prevent others from rescuing his insights about art from his overall framework. As for Deleuze, what might we say is his approach to rejuvenating art history or aesthetics, and how might we develop this approach to provide resources for a raced and gendered approach to art?

A feminist or raced approach, we might assume, would require reference to a feminist or raced agenda and to a specific constituency of viewers that might be understood as a pre-existing culture. Such approaches might also be understood to 
require that images be representative of certain communities or ideas. In what follows I want to complicate such assumptions.

Ionsescu formulates Deleuze's goal in his approach to the arts as not a question of interpreting 'the visual arts as a practice that mirrors pre-existing culture' but rather a question of determining 'the potentiality of visual arts to modify the view one has of the world' (2017, p.26). Ionescu tends to set up an opposition between 'the self-referential position where artworks are interpreted as representing the environment from where they emerged' and Deleuze's 'intensive model where various artifacts generate an atlas of sensations that spread cross-historically and cross-culturally' ( $p .28)$. If art is not understood as mirroring pre-existing culture or self-referentially, we might surmise that there is little scope for developing a Deleuzian account of art that is also feminist or responsive to issues of race.

A tension is evident in how Tuinen and Zepke negotiate the complicated relationship between aesthetics and politics. They gloss the political as an area of life 'largely determined by human consciousness', one that does not 'tend to play a decisive role' in Deleuze and Guattari's understanding of art works as 'expressions of immanent and abstract forces that animate all aspects of our world, and indeed what is not ours, the cosmos' (2017, p.7). By way of explanation, they go on to explain that forces 'do not obey "ideas"' but rather 'emerge through the materials that actualise them, through the abstract movements, machinic relationships and often unconscious and inorganic motives of "matter-force"' (p.7). Note that in this articulation of forces as distinct from that which would obey ideas, almost by default, the political is aligned with 'consciousness' and 'ideas' are pitted against the 'unconscious'. At the same time, Tuinen and Zepke acknowledge that the work of art expresses 'force according to its own conditions' and that these conditions 'can, through the processes of expression, themselves change'. They can also 'include the political'. Yet, in their (quasi-Hegelian?) assumption that the political can be broadly aligned with that realm of life that is determined by human consciousness, and in their suggestion that, by contrast, the forces that get expressed through art do not obey ideas, in effect they have cordoned off all kinds of ways in which art might operate politically. Given that politics is cast on the side of human consciousness and ideas on the one hand, and is implicitly opposed to art, which for its part is cast on the side of the immanent expression of forces, there might seem to be little possibility of investigating the ways in which the conditions in which a given work or art is allowed to flourish or not are infused with both political and aesthetic assumptions.

Yet there is a large body of work indicating that far from involving human consciousness, or being formulated as coherent ideas, discrimination and prejudice often operate in ways that are unconscious (Sue, 2010). There is also significant scholarship suggesting that feeling, emotions and affects are politically laden (Berlant, 2004), so that to invoke feeling as opposed to meaning is somewhat heavy handed. This in turn suggests that art which is capable of tapping into forces and feelings that are often unconscious might well be implicated in the political, that the political valence of art is not restricted to representing the environment from which it emerged or to mirroring pre-existing cultures, but might also be capable of modifying the view one has of the world. It might be just as capable of migrating cross-culturally, perhaps cross-historically as any other art. Perhaps the oppositions lonescu sets up-either representation or sensation, either emanating from a particular culture, or capable of modifying the world, need, then, to be rethought.

As he goes on to develop his investigation into Deleuze's relation to art history and his manner of writing it, lonescu's account provides hints as to how works of art can both be implicated in representation of a particular culture and possess the ideological power to break away from it, and to disturb rigid forms of life.

According to lonescu, Deleuze's contribution to art history is to construe it as 'essentially a constellation of sensations' where 'this constellation is a force that can overcome historical delimitation' (2017, p.28). For Deleuze, art can, lonescu claims, 'still represent the culture that created it but it has an artistic value precisely when its intensity breaks with its environment and affects other ages, cultures and people. . . the object of art is an anonymous force that has the potential to migrate through the world' (p.28). Art is 'a process of "weaving" sensations that disturbs any enclosure of life in rigid forms' (p.28). Although he does not elaborate the claim, for lonescu, Deleuze's 'impersonal and transitive conception of painting has an ideological power: this culture of transformative repetitions and perpetual transitive processes resist the stability that systems of power implement on language or the body' ( $p .33)$.

At one point, although they refrain from providing it themselves, Tuinen and Zepke also situate, and perhaps even call for, such an investigation, when they say, 
While a politicised art history is clearly possible (ie T. J Clark), and arguably fundamental to feminist art history or 'new art history,' it generally tends to follow the political commitments of those artists discussed . . . rather than develop an aesthetics as political strategy. Certainly the militant Guattari insisted that the aesthetic paradigm was first of all political $(2017$, p.17)

I would not so much want to develop an aesthetics as a political strategy (which might result in the subordination of aesthetics to a particular politics), but rather to keep a space open in which the conditions under which certain art works might be said to express certain forces can be interrogated. For how these conditions are understood, as well as how forces of certain artworks 'not only to express, but also actively construct' a [Bersogian/Deleuzian] 'open and changing whole (duration)' (p.10) is itself open to political dispute. In this sense, it would be necessary to say that the very identification of a minor, as opposed to a major, literature (or art) can be a contested question, so that to take up a term such as 'minor' is not necessarily merely a question of applying a Deleuzian concept that was invented in relation to a singularity, and thereby turning it into a generality or into the 'conformity of a law', as lonescu maintains it is (p. 21). If what constitutes the field of literature, or the sphere of art are themselves not stable arenas, but rather are contested, neither can the meaning and application of terms such as 'minor' be taken for granted.

Whatever else we can say about the relationship between politics and art, it is one in which both terms must remain contested. What constitutes politics and what constitutes art must remain, to some extent, in question. One of the ways in which politics operates to support the status quo is to deny that certain claims or certain spheres of life, among them the aesthetic, are political. Accordingly, part of the work of politics is to demonstrate that the conditions that facilitate the expression of a work of art are in fact political, and not just the way things are. It is not a question of either reducing the work of art to narrative or generating new concepts, but of modifying the world in such a way that new narratives can become intelligible, can begin to be seen, that their prior invisibility can also be registered and that new concepts might be formulated in the wake of their new visibility.

The vehicle I have chosen to explore the contested site that art constitutes is an exhibit at the Tate Britain, All too Human, which features the work of Francis Bacon and Lucian Freud and includes other artists such as William Coldstream, Euan Euglow, Paula Rego, Stanley Spencer, and Lynette Yiadom-Boakye. The title of the exhibit performs a reference to Nietzsche's Human, all too human, subtitled: $A$ book for free spirits. In citing Nietzsche, are the curators of the exhibit calling up the foibles of us mortals who take ourselves for gods ('so that you finally stop wanting to be the only god' says Irigaray? (1991, p.25). Are they also bringing into question the ease with which we seem to replace one god with another (the all too human displacement of religion/fetishism/commodification/corporate markets ...)? Is there a sense in which at least some of the artists featured in All Too Human, gathered together under an exhibit title that recalls Nietzsche, manage to avoid a similar fate? I would say that there is.

In the decadent languid sorrowful sweep of David Dawson's aquiline limbs, echoed by the muted colours of Eli the dog, curved into tranquillity beside David in Freud's 2003-4 David and Eli, what is it that haunts Lucian Freud? Is it David's apparent complete lack of proclivity for worship of any kind of deity? Is it David's apparent carelessness, almost laziness, indolence, as if he has drunk one too many glasses of liquor, or has just awoken from the torpor of a Sunday afternoon slumber? Perhaps he has just had sex and is bathing in its afterglow. Perhaps he is simply tired of posing for Lucian. Perhaps he has been dreaming. Perhaps he is coming down from being vaguely aroused in a nonchalant sort of way. Whatever it is, there is something liquidly alive in this painting, something that stays with me long after I walk away from it, following me out of the gallery and into my life, just as David's foot dangles from the chaise-longue, which refuses to entirely contain the labile quality of his supine figure, his slightly dishevelled, aging, far from perfect but still rather beautiful thin and slightly sagging body. Eli's head hangs off the divan too, mirroring David's foot.

A plant stands next to David and Eli. The leaves of this large plant in its off-white wicker container are spiky to a point, but some of them droop, like David's penis, its leaves are as green and brown as David's flesh is pink and red and brown and white. Freud has applied the paint so thickly at certain strategic points of David's body, his knee, for instance, that it almost cracks, there are globules, knobs of paint, creating a surface that would be rough to the touch, so worked over are some portions of David's flesh. Impasto. Not only, then, is Freud exploring David's animality, in aligning him with Eli. He is also exploring his plant-like features. In this sense he might be said to be approaching what Deleuze would later interrogate as becoming-animal, or becoming-plant.

Deleuze and Guattari ask in Kafka: Toward a Minor Literature: 'Isn't it rather that the acts of becoming-animal cannot follow their principle all the way through - that they maintain a certain ambiguity that leads to their insufficiency and condemns 
them to defeat? Aren't the animals still too formed, too significative, too territorialized? Doesn't the whole of the becoming animal oscillate between a schizo escape and an Oedipal impasse?' (1986 15).

Freud's figure is not quite human, more animal than human, almost plant-like, but its way of being not quite human is vastly different from how Paula Rego's figures, also included in the exhibit, are not quite human. Foreshortened, contracted, compressed, there is something doll-like about these figures, something that resonates with the large, placid eyes staring out of the flattened face of Freud's Girl with a kitten (1947) in which the hands of a frizzy haired woman, all blue and grey and brown, hold a kitten in a stranglehold. Yet the cat is unperturbed, its green eyes staring out calmly at the viewer, while the girl's eyes look off at an angle. All very controlled. Very mellow. Very calm. Almost too calm. Skin like porcelain, wide almond eyes. Only the fizziness of her hair is not calm. Rego, on the contrary, stages her figures in bustling rooms, in busy and demanding scenarios.

Within the large frames of her paintings there is none of Freud's serenity borne of his singular focus. There are regimes to be glimpsed, rubrics looping together her disparate, distended bodies, loosely tying the figures to one another in misunderstood, unconceptualized, perverse relationships, as if the emotions which preoccupy each of the figures in their own way disconnect them from one another even while stemming from their shared, compacted histories. Each figure is caught up in their own affective world, bound to the others only through their uncognising differentiation. There is laughter, power, aggression, determination, ridicule, derision, complicity, submission, boredom, torpor, exhaustion, carelessness. And there is refusal. There is a wrist caught in a hand, an elbow that has given up flailing, the twist of a head, a reckless almost smile, the straightforwardness of just standing one's ground with sturdy feet, akimbo, and not giving up on one's desire-however problematic it might prove to have been at some future as yet unmarked point in the passage of time that is, inevitably, to come.

There is a darkness to these paintings. Whose is the suit hanging in Shipwreck? It is small enough to be a boy's, but no boy appears in the painting, only a man. Has it shrunk? Why are the drawers of the cabinet so higgledy piggledy, what's a parrot doing perched on the chair, who is the dog in the foreground snarling at? Is it us? Why is a black doll sitting on the floor amidst open books and files? What is a blue urn doing besides the open drawers? Why is a carpet climbing up the wall, where's the ladder, buttressed right up against the chair, upholstered deep red, in which both of the central figures of this painting are located, reaching up to? The dark-haired woman seated in the chair looks off to her left. She is underneath a man who lies across her, eyes closed, fast sleep; she supports his weight. She cannot be that comfortable. He must be heavy. Her bare legs are apart, her feet in black shoes, planted on the floor help bear the man's weight. The man is peaceful, oblivious to the chaotic room around him, lost to the world. And she seems to be taking everything in her stride.

Is this the same woman pictured in the second of this triptych, seated under a large hair-dryer, her daughter, perhaps, sitting by her side, gazing upward into the mirror, into which her mother also looks? I think so. Although unlike her daughter, we cannot see the mother/the wife's reflection in the mirror. Curiosities populate this painting too. This time a gold coloured ashtray, shaped like a monkey. Vestiges of Portuguese and British colonial slavery regimes. The woman same woman, perhaps, is wearing a black jacket and bright green skirt, looking askance in the first picture of this triptych, a response-a riposte-to Hogarth's The Marriage a la mode. Here too mirrors reflect figures whom we do not see otherwise in the painting. In the foreground a child, sprawled in her white dress on a chair, caresses a dog with her foot. In one of the mirrors a woman in underwear is removing her tights while a man, his back turned to us, looks on. In the middle of the painting a man crouches for solace against the older woman to whom the woman in the black jacket might be conversing. Behind them a still older woman looks aghast. At what exactly, it is unclear. At the woman in a state of undress, whose mirrored reflection we see in the background of the painting? The decaying stages of a marriage, perhaps. And yet, there is something robust, at least about the woman in the final painting. Of course, none of these questions are ultimately answerable, and nor should they. As Deleuze puts it, 'painting itself is beyond all narration' (2017, p.50).

Although Rego might have been pigeon-holed into a representative framework, and might even have contributed to allowing herself to being pushed into such a framework through her own commentary, it could be argued that what matters above all in her paintings are the ways in which the energy that flows through the figures she depicts interacts with the force fields within which they are situated. There is, for example, in The Bride, a naked sadness, a solitary refusal, an acute discomfort, an intensely private rebellion against invisible forces made visible, the forces of decorum that organize this bride into strictures she escapes, fleeing her wedding dress cage. For Deleuze, rhythm, 'appears as music when it invests the auditory level, and painting when it invests the visual level' (2017, p.32), and it is rhythm itself that would constitute the Figure' (p.51). The rhythm invested in this painting is one of flight, it is a minor reterritorialization. It is a throwing off of shackles, a 
withdrawal from convention, a re-assignment of oneself away from marriage in the midst of it. It is a wrenching of the body away from everything that would tame it, manipulate it, and control it.

Rego's figures are orchestrated by forces over which they do not seem to be in control, by a web of calculation and desire to which they are in thrall, and which only becomes visible through their facial and bodily reactions, their torpor, their amusement, delight, ironic detachment. Desire overwhelms them, fear paralyses them, or indulgence overcomes them. The passions that circulate from one to another are not so much indicative of a story that is being narrated involving characters in relationship to one another as of the intensities of the passions themselves that course through them. The figures themselves are at the mercy of these forces, cowed by their strength, assaulted by them, rendered diminutive in their efforts to navigate them, incapable of distinguishing themselves from the fields of emotive forces that seem to flow so freely and excessively, binding these figures to one another even as they hold them apart. Racked with emotion, they are mere vessels. The social/psychic mores, and their transgression of them, that throw them together and keep them apart from one another dictate their movement and their stasis.

There are variety of ways in which the figures in this exhibit might be said to depart from their figurations, deviate from the human, becoming almost non-human, almost inhuman by being all too human. Stanley Spencer's Nude Portrait of Patricia Preece (1935) departs from the historical conventions of female nudity, an uncompromising, confrontational expression in her eyes, the insistent networks of tiny blue blood vessels tracing their way across her sagging, spreading, very large breasts. Not pendulous. Pendulous is a word men who don't have breasts tend to use for women who do. To use such a word for a breast makes it sound like some kind of appendage, which just happens to be tagging along with the rest of the body, an optional extra. The two breasts are different shapes from one another. The left breast, to the right of the painting, slides off to the side, as if trying to escape the vision of the painter altogether. How much this has to do with the uneven angle of the shoulders, the right one held higher than the left is hard to tell. The more one looks, the more one finds the lines in this painting to be crooked. Patricia's eyebrows are almost demonic. Her left eye, like her left breast, looks slightly off to the side. It is hard to tell whether in fact her right breast is really larger than the left, more bulbous, or if it is merely angled differently due to the poise of her shoulders, which make the left breast wander almost out of the painting. In the middle of her chest, the skin has a high colour, almost as if it had been scratched due to an itch, and is slightly irritated. Lines furrow the skin of her belly, one line appears just beneath her breasts, cut off from vision by the bulging fullness of the breasts. Some traces of navel hair creep up toward the brown hollowed dent of her tummy button.

There are other paintings of female nudes (or almost nudes) in the exhibit, but none confront the viewer in the way that Spencer's painting of Patricia Preece does. They are too vague, somewhat apologetic. William Coldstream's Seated Nude (1952-3) is rather washed out. The figure is a bit wan. Coldstream's Seated Nude of 1973-4 is depicted from a sideways angle, mouth slightly ajar, a little disconcerted, smallish breasts, solid thighs, the model doesn't look too comfortable. She is not at ease. As l'm contemplating her unease, on one of my visits to the Tate Britain, the voice of a seven or eight-yearold says from behind me: Is that a man or a woman? I can see the point of her question. There is something that could be read as conventionally masculine about this figure, whose pubic area is hidden from view due to the angle in which she is seated in relation to the viewer. There is something angular about her shoulders, her chest, something that is not coded as conventionally feminine in the way she allows her lower lip to drop, in such an unselfconscious manner. What do you think it is asks a mother-voice behind me. The child is unsure, that's why she asked the question. It's a woman! Comes the follow up. In the beat of time that passes between the question and the response I resist turning around to engage the child in a discussion about sex, gender, trans issues and so on. My guess is the mother wouldn't appreciate such an intervention. So I let it go, drifting along in my thoughts about the ease with which this question is answered, about how Freud's question, am I a man or a woman, am I an obsessive or a hysteric has been forestalled for this child's reading of Coldstream's seated nude. I wonder if it is foreclosed forever.

There's a painting by Euan Uglow, Georgia (1992). Georgia is not nude, but she might as well be. Her simple, white, tight fitting dress, with its three bands of red around the cuffs and the neck reveals that she is bra-less. Her nipples protrude beneath the material that clings to them. She looks rather bored. There's an intense eroticism about this painting, and it is the only one of the exhibit that even begins to approach the confrontational air of Spencer's Patricia, whose eyes, under those quizzical, offbeat eyebrows, would almost burn a hole in your soul if you let them.

For his part, Bacon exploits the boundary between the human and the inhuman still further. Taking body parts and stretching them out along planes and axes they were not meant to be stretched across. Contorting the body into impossible, inhuman positions, tying it up in itself, spreading it out from itself, like butter spread on burnt toast. His paintings have the rasp of a 
knife across the crisp surface of overdone toast. And that dog. Bacon calls it simply Dog (1952). Dog paces in a circle, as if in a compound. Hunted. Caught up in his own demise. No barbed wire encircles him. Only his own infernal constriction. Only a not quite hexagon shape against a red background, a floor of sorts, containing a painted green circle, within the bounds of which dog turns on himself. Deleuze (who does not discuss this particular painting) might identify this as the isolating contour. Except for one of his hind legs, which falls just outside the circle. Dog looks hot, thirsty, parched. His red tongue hangs out. The whole canvas has a torrid feel to it, perhaps because of all that hessian, giving the impression of a desert, of sand. Bacon said his paintings were about sensation. ${ }^{1}$ The sensation here is heat. And fear. And constriction. Beyond dog, in the middle distance there is a thin blue line reaching from one side of the painting to the other (is this thin blue line the sea?), across the hessian coloured canvas, which looks as if it has hardly been painted. A solitary palm tree accompanies the thin blue line of the sea. In the far distance is a further single black line. A horizon. Dog has none of the passivity of David's Eli, all of the tautness of fear and watchfulness, as if it might have been beaten. Such intensity, coiled into the curve of its back. Waiting, just waiting for something else bad to happen. Almost human.

There is something almost comic about this piece. Between the red not-hexagon and the thin band of sea are several cars, all black, proceeding in both directions along what must be a highway. They are like toy cars, with multiple black lines trailing from each of them, tapering off, indicating the speed at which they travel. Similar lines indicate the motion of dog, whose face is darker than the rest of his body, which is so cowed.

Like Dog, the figures of Lynette Yiadom-Boakye are also tense and watchful, but for more diffuse reasons. How do the subtle and shadowy ways in which Lynette Yiadom-Boakye's figuration of race and sometimes ambiguous gender help to recast racialised and gendered regimes? Two of her paintings book-end the exhibit, almost a footnote, all but an afterthought. bel hooks says somewhere that African-Americans are often appended to the end of feminist syllabi. The course is about 'us', but then there's a nod, right at the end to the others. Not a nod that makes the others central, merely a nod that acquiesces to share some space with these others, space 'we' still control, space we 'allow' these other into, as if it were ours to give. This feels a bit like that. Lynette Yiadom-Boakye's paintings flank the exit door. You could almost miss them altogether, on your way to get coffee.

Still, they are there. That's something. There is a restlessness about the figures in these paintings, a quiet, self-contained energy pulsing through them, a disdain in the way they place their hands on their hips, as in The Host Over a Barrel, or form a diamond with their fingers, as in Coterie of Questions, sitting pensively, or standing, waiting for an unseen event, a car, a person, for time to slip silently away into something unexpected. Is there a car, shining its headlights from outside the frame of the painting, lacing a brightness around three figures, all wearing short, dark, sleeveless dresses, all, more or less, with their backs to us? What are they waiting for? A feeling of not being quite at home. A looseness but one that is studied, deliberately assumed. An attitude taken up for the world. Masks adopted for the purposes of survival. Like the 'large rings and medallions', 'the big puffy coats and full-length fur-collared leathers', like the 'gilded bamboo earrings' TaNehisi Coates recalls being worn by the 'extravagant' boys and girls on the Baltimore streets of his youth, who stood around pumping music 'from boom boxes full of grand boast and bluster' covering their fear with loudness and bravado (2014, p.14-15). Each of Yiadom-Boakye's figures strikes a pose. A very deliberate pose.

Even if first appearances might suggest something approaching flippancy, it would be a mistake to read anything casual in the way these figures, black on grey, stand their ground. They are not so much silhouetted against the darkness of the night as cast in chromatic progression against it, limbs outlined against the murky, hazy, uncertain backgrounds in which they are set. What one sees, if one looks for a while, is forbearance. Endurance. Fortitude. And weariness. A certain lassitude permeates these images. Like they have just witnessed one of the series of all too many all too frequent all too human micro-aggressions Claudia Rankine describes so painstakingly, with such precision in Citizen: An American Lyric (2104). They have just been overlooked at the cash register in a drugstore. Rendered invisible, negligible, non-existent. Oh, I didn't see you. No, I really didn't see you. Or they are about to be. Or they will be the next day, or the day after that. The daily grind of racial diminishment, Rankine calls it.

The steady drip, the pressure of life, of just trying to survive, of getting by. Drips that cumulate in pools, sometimes pools of tears, sometimes of blood, caused by knives. Or guns. These figures might very well have just witnessed a murder. They might be about to witness one. They hold this knowledge in their stances. The precarity of their existence. The fragility of 
their lives. It is not for nothing that they are wary. In their stances they defend themselves against what might happen. Against what all too easily might happen, against what all too often keeps happening, will keep on happening unless very many intricately interlaced things change, things that are woven into the very fabric of society, things that get so easily passed over by those of us who can pass over them all too readily. The unwary ones. Lack of horizons, lack of possibilities, systemic failure of the very basic provision of what most of us consider to be necessities, not luxuries. Health. Care. Sanitation. Food. Safety. Security. Accommodation. Sanity. Being able to live lives that are not caught up in trying to ascertain things that need to be taken for granted, to fade into the background, in order to free oneself up for the pursuit of education, art, intellectual activities, earning a decent living. In order, we might say all too simply, to succeed in life.

One might say that an atmosphere of submission permeates this painting, but that one of perseverance, overcoming, survival is in ascendance. We could express this In terms of what Deleuze refers to as the diastolic and the systolic, in terms of a 'crescendo, or simplification, climbing, expanding' and 'adding value' meeting a 'diminuendo or elimination (descending, contracting, systolic, removing value)', and creating a rhythm with a third element, perhaps the attendant element, the damp misty haze of the night air, in which the balance of the diastolic and systolic is played out, and into which it dissipates.

There is patience, waiting, watching, passivity in their forbearance. Watchfulness. As if time itself were suspended, as if it stood still. 'The instant ... reverts to tranquillity in waiting' says Levinas, 'Neither anticipation nor impatience, 'waiting waits for nothing (1989, p. 51). There is little action, little movement in Lydiam Boakye's paintings. Time is distended. Hours might have passed, and still these figures would be arranged in their poses, watching and waiting. To see what might happen. As if their narratives are not of their own making, as if they are mere spectators in someone else's show, a show that they have decided to bring to a halt. As if the continuity of time itself were forestalled by their very restless stillness, through which they offer resistance. Here it is not so much a matter of resisting the stability that systems of power implement but rather a matter of remaining still in order to resist the dynamism of systems of power that operate as if those who withstood it don't exist. There is a jadedness, a wariness to be sure, but there is also a steadfastness, an affirmative we shall not be moved.

It is in a zone of indeterminacy that the correlation and difference of Levinas and Deleuze on rhythm in art might be placed. For Levinas, every art work is a statue, which slices through time, immobilizing it, freezing it, according it a truncated rhythm of its own, a rhythm that transports the viewer. The art work interrupts time, as if creating a stoppage. There is at once a proximity and divergence when it comes to how musical rhythm is taken up by both Levinas and Deleuze and re-envisioned in relation to visual art.

In the context of the exhibit, one might call it an assemblage, All too Human, it might be said that Rego and Lydiam-Boakye operate as protagonists of minoritarian art, and that Spencer and Uglow approach such a status. If lonescu is right to suggest that Deleuze's approach to art can be characterized as a 'constellation of sensations' understood as a 'force that can overcome historical delimitation' I have sought to demonstrate how Lydiam-Boakye, Rego and Spencer in different ways have mobilised sensations, constellated them in such a way as to bring into view figures who have typically been relegated to the background of art history. In rendering visible the rhythms in which they are caught up, and how these rhythms are a function of specific temporal modalities that infuse these works (frenetic and conflicted, in the case of Rego, whose figures seem to contract under the very weight of the passionate regimes in which they labor; passive, watchful, slow, almost a stoppage of time, wary, cautious, steadfast in the case of Lydiam-Boakye's patient, world weary but also potent stances) I have tried to illustrate how such work can in lonescu's words 'still represent the culture that created it' but have artistic value precisely because of a transformative energy and 'its intensity breaks with its environment and affects other ages, cultures and people'. In doing so, I hope to have fleshed out the sense in which even as Rego and LydiamBoakye, who put female and black bodies at the centre of their paintings, and in some sense represent specific communities, they do so not in order to present forms that are homologous with and reducible to a certain constituency or culture, but in order to precisely allow these figures to break out of such scenarios, and to migrate elsewhere. Such migrations might unsettle the stories we tell ourselves about majoritarian and minoritarian figures, stories that continue to haunt in some predictable ways even Deleuze's renewal of art history.

\section{References}

[1] Baranova, J., Junutyte, L. \& Duobliene, L. (2016). Rhythm and Refrain: In Between Philosophy and Arts, Vilnius: Vilnius University, Lithuania. 
[2] Berlant, L. (2004). Compassion: The Culture and Politics of Emotion. London: Routledge.

[3] Coates, T. (2015). Between the World and Me. Melbourne: Text Publishing.

[4] Deleuze, G. (2017). Francis Bacon: The Logic of Sensation. Tr. Daniel W. Smith. London: Bloomsbury.

[5] Deleuze, G., \& Guattari, F. (1986). Kafka. Toward a Minor Literature. Tr. D. Polan. Minneapolis: University of Minnesata Press.

[6] Ionescu, V. (2017). Remake/Remodel: Strategies of Reading Art Historians. In S. Van Tuinen and S. Zepke (Eds.) Art History after Deleuze and Guattari (pp. 21-39). Leuven: Leuven University Press.

[7] Irigaray, L. (1991). Marine Lover of Friedrich Nietzsche. Tr. G. Gill. New York: Columbia University Press.

[8] Levinas E. (1987). Reality and its Shadow. In Lingis, A. (Ed.). The Collected Philosophical Papers (pp. 1-13). Dordrecht: Martinus Nijhoff.

[9] Levinas, E. (1989). The Servant and her Master. tr. Michael Holland. In The Levinas Reader, ed. S. Hand (pp.151-159). Oxford: Basil Blackwell.

[10] Peppiat, M. (2016). Francis Bacon in Your Blood: A memoir. London: Bloomsbury.

[11] Peters, G. (1997). The Rhythm of Alterity: Levinas and Aesthetics. Radical Philosophy 82 (March/April, 1997), 9-16.

[12] Rankine, C. (2014) Citizen: An American Lyric. Minneapolis: Graywolf.

[13] Sue, D.W. (2010). Microaggressions in Everyday Life: Race, Gender, and Sexual Orientation. New York: John Wiley.

[14] Van Tuinen, S., \& Zepke, S. (2017). Introduction. Art History after Deleuze and Guattari. (pp.7-19). Leuven: Leuven University Press. 